\title{
Framework of Using Techniques in Human Resource Management in Vietnamese Companies
}

\author{
Thuy Nguyen Thi Thu \\ Thuongmai University \\ 79, Ho Tung Mau, Mai Dich \\ Ha Noi, Viet Nam \\ Email: \\ thuynguyenthithu@tmu.edu.vn
}

\author{
Bich-Loan Nguyen \\ Thuongmai University \\ 79, Ho Tung Mau, Mai Dich \\ Ha Noi, Viet Nam. \\ Email: \\ Bichloandhtm@gmail.com
}

\author{
Trung Nguyen Chi \\ Hanoi National University \\ of Education \\ 136 Xuan Thuy, Cau Giay \\ Ha Noi, Viet Nam. \\ Email: trungnc@hnue.edu.vn
}

\begin{abstract}
The COVID-19 pandemic requires many companies changing the way of their operations because of the lock down of movement and limitation of facing contact, etc. This also is an opportunity for companies to utilize technology and use digital space to keep their works and companies' activities. Companies can encourage their labors via policies of promotions. However, how to evaluate employee performance fairly, unbiasedly, and transparently? The existence of AI (Artificial Intelligence), especially machine learning, might be a solution for this due to the fact that it can automatically evaluate individual workers' performance. Therefore, the performance evaluation process ensures that the system works without interference from people outside of the system. In the paper, a framework of KPIs building systems to evaluate individual workers is represented as a solution for applying the advantage of AI (machine learning techniques) in Vietnamese companies. It can help them to improve the labor productivity and increase the workers' quality in the labor market in general.
\end{abstract}

Index Terms-Human Resource Management; Machine Learning; Artificial Intelligence (AI); Techniques; individual KPIs.

\section{INTRODUCTION}

$\mathrm{H}$ UMAN resource management activities also have been changed with the significant development of the Fourth Industrial Revolution. At the beginning, human resources work mainly related to supervision, salary calculation, bonus, welfare and labor safety. The human resource management process became easier with the help of computers, internet, etc. The more development of technology, the more convenient the management of human resources can be. Therefore, human resource activities have time to focus on recruiting and attracting talent employees from alternative resources as well as improve the optimization of management in work allocating.

The challenges for many companies in COVID-19 pandemic are the lockdown of movement, limitation of facing contact, etc. All these might provide opportunities for companies to utilize technology and use digital space to keep their works and companies' activities. The existence of AI (Artificial Intelligence), in particular to machine learning such as chat bot, might let many people to concern about the fear of being replaced [8]. However, the existing of AI here means helping people in their works as well as improving their work performances. For example, by using machine learning techniques, human resource recruiters can be able to select the right employees from many talent profiles in the massive selective job platforms.

The term artificial intelligence1 (AI) started in the 1950s, which tried to build a machine to mimic people's thinking. By that time, the development of AI is wide with the abilities of deep learning, problem solving, recognizing etc. Machine learning is a main field of AI in which people can teach the machine (computer) doing. According to [6,7], machine learning can be applied widely in alternative areas because it can create outcomes from diverse domains. Machine learning going with AI technologies also offers many significant opportunities and challenges to organizations. For example, it might change an organizational structure such as the capacity to constrain, complement, or substitute for humans at work [13]. These changes might shift the management from the exclusive domain of humans to a new method of management and it requires the development of a combination between machine working (with $\mathrm{AI}$ ) and human beings in new ways to establish a new method of work, or new forms of work in the company $[1,2,11]$.

In Vietnam, not many Vietnamese companies have used this advantage of AI particular machine learning techniques because of the expensive system installation. However, nowadays, the cost of SaaS (software as a Service) can help the company cut down the cost of system deployment. Therefore, Vietnamese companies have a chance to apply the advantage of innovation of Technology such as machine learning in their business, in particular to human resource management. The research objective here is applying the advantage of machine learning techniques in human work's performance evaluation sector by using the framework of work's performance evaluation system with machine learning techniques such as clustering. This is because the machine techniques can ensure the performance evaluation system to perform independently without the involvement of people outside the system. This leads the system becoming a transparent, fairness, and trusted evaluation one. 


\section{LITERATURE REVIEW}

A. The challenges to human resource management in Vietnamese companies

In general, the use of human resources with machine learning can be seen as the transformation of human resource services with the help of using AI to support the decisions in employees' works.

Vietnam ranked the $48^{\text {th }}$ over 100 for the structure of production as well as the $53^{\text {th }}$ over 100 with factors leading to production according to WEF [3], in 2018.

On the side of human resources, Vietnam also only stops at 70th position, in which the indicators of highly skilled labor and university quality are also low (ranking 81st and 75th respectively). In the ASEAN region, in terms of innovation technology and human resources rankings, Vietnam ranks behind Malaysia (with ratings of 23 and 21 respectively), Thailand (41 and 53), and the Philippines (59 and 66). Although information technology in Vietnam has significant growth nowadays, the requirements of training high quality human resources who are adaptable to the innovation are necessary.

The inevitable trend of the 4.0 technology revolution will impact the supply and demand of labor as well as the shift in labor resource structure. In the process of transforming labor structure, improving the quality of human resources is urgent [4], [18]. According to [14], [15] the opportunities and challenges that Vietnam faces in the Fourth Industrial Revolution are: Vietnam has a dynamic economy and a young population, so it is easy to access new technologies of the Fourth Industrial Revolution; The large market size and relationships with many countries around the world are good conditions for the production and exchange of goods. However, Vietnam has not yet met the high-quality labor force. Besides that, the phenomenon of brain drain is happening. This is because of the policy of attracting talent from International companies and the free labor movement in the ASEAN region. This phenomenon makes the labor force in Vietnam increasingly in shortage.

Here is a context in the Vietnamese labor market. In Fig. 1, the total of employed workers is 53.61 millions in alternative employment status. This takes up half the proportion of the Vietnamese population (over 98 millions).

\begin{tabular}{|c|c|c|c|c|c|c|}
\hline & 10 & 20 & 30 & 40 & 50 & 60 \\
\hline Wage worker & & & & & & \\
\hline Own account worker & & : & $5 \dot{6}$ & & 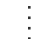 & \\
\hline Family worker & & & : & & : & \\
\hline Employer & $1.4 \dot{5}$ & : & $\vdots$ & : & $\vdots$ & \\
\hline Member of cooperative & 0.09: & : & : & $\vdots$ & : & \\
\hline
\end{tabular}

Fig. 1: The number of workers with employment status in Vietnam in 2020, (in millions)

(Source(s): General Statistics Office of Vietnam; Statista, 2021)

In Fig. 2, the rate of workers in rural areas is more than double that of urban. This is appropriate to the Vietnam population characteristics of an agricultural country. However, there is not much of a difference between rural labor and urban labor.

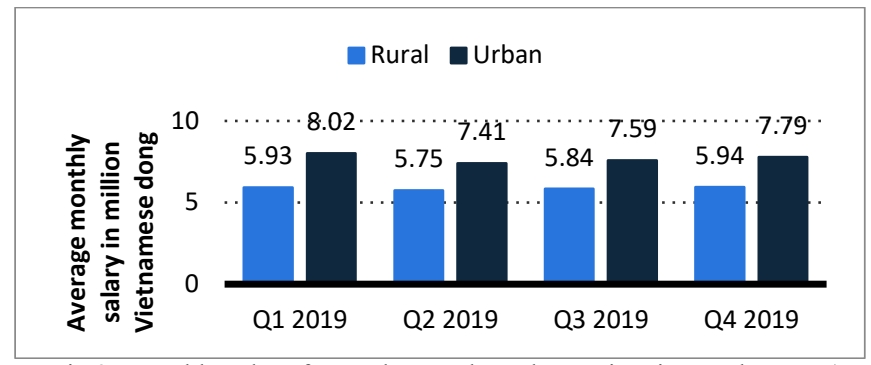

Fig 2: Monthly salary for workers and employees in Vietnam by area (on average) in 2019

(Source(s): General Statistics Office of Vietnam; Statista, 2021)

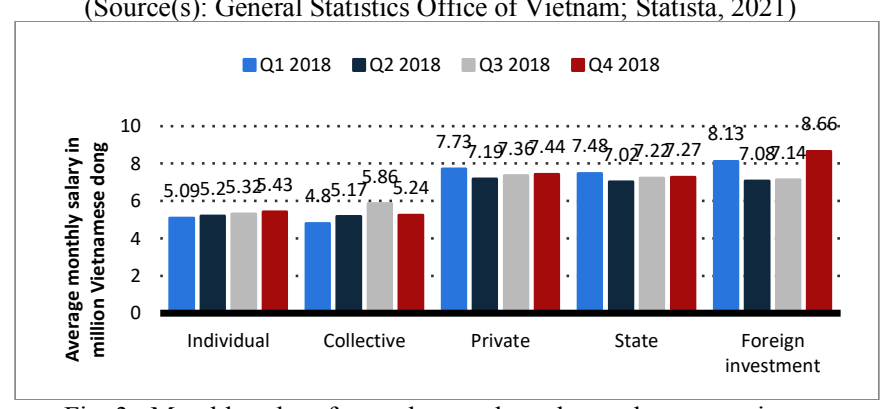

Fig. 3: Monthly salary for workers and employees by economic sector and unit in Vietnam (on average) in 2019.

(Source(s): General Statistics Office of Vietnam; Statista, 2021) According to Fig. 3, the highest rate of monthly salary belongs to foreign investment companies. There is not much different salary payment between private and state sectors.

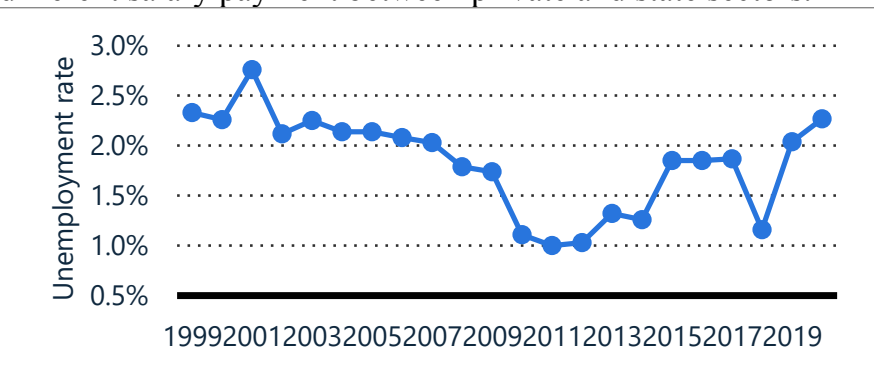

Fig. 4: Unemployment rate in Vietnam from 1999 to 2020.

(Source(s): General Statistics Office of Vietnam; Statista, 2021)

The unemployment rate in Vietnam is fluctuant. The unemployment rate is up from 2018 to now. This might be the unexpected impact of COVID-19 pandemic.

Almost all Vietnamese enterprises in Vietnam are small and medium-sized (SMEs). Their companies contribute to society by creating jobs for workers. For example, they create more than 500,000 employees every year, and hire about 50\% social workers. They contribute to the nation over $40 \%$ of GDP every year [20]. However, there are very few small and medium enterprises that have long-term human resource planning. According to statistics [20], almost all the recruitment from investigated enterprises is based on the replacement of workers. In these recruitment, there is about $15 \%$ of replacements with the changes of many factors such as science, technology, new requirements of products and services, capital scale, etc.

In Vietnam, in many companies, the number of demanding planned labor shortages is calculated by each department in the companies. This is based on the current workload and normally done without the participation of the human resources department. In these companies the functions of the human resource management department are receiving labor 
demanding from other departments and conducting recruitment. Therefore, to make a prediction of the forecast of human resources for further years is not interested or paid attention in Vietnamese companies in particular small or medium companies.

\section{Job analysis}

The brief detail of job analysis or description is only done in medium enterprises with a size of 50 employees or more. There is no common job description form. But the general template for drafting job descriptions can be as: Job title; Name of the department in charge of the job; Supervisor's name; Brief description of the job; Standards for getting the job done; etc. There is no existing job analysis. It is only conducted when there is a vacancy in the enterprise. There are a few companies, who have used a process to build job analysis, whereas many others do this by individual staff in the human resources department.

\section{Recruitment}

Vietnamese enterprises usually use two resources for recruitment. Firstly, the employees are recruited from internal recruitment sources. When the recruitment is carried out, the administration department will send an announcement to other departments or to the board of the enterprise system. Each department will consider the individual who is able to take on the job. Then, the company's departments will inform the administration department about the candidate.

Secondly, the employee can be recruited from outside. Currently, the recruitment through job agencies is still very limited. In fact, there are not many professional agencies who can assure the quality of the human resources for enterprises. The job agencies now operate their activities as the job exchange market. The sources from training institutions and the mass media are part of ensuring that businesses hire the right people for the right jobs. This form is usually used with enterprises having 50 employees or more. The common method of recruitment is announcements which are made via the Internet and newspapers. According to statistics [20], there are about $25 \%$ of enterprises recruiting through these mass media. This rate reflects the low rate of using technology in recruiting compared to other countries such as Asian countries.

Depending on the level of awareness and management, the effectiveness of the recruitment process is normally not evaluated. So, there is not a professional process of recruitment in Vietnamese companies.

\section{Performance evaluation}

Many Vietnamese companies use the scoring method to evaluate staff's performance. However, this evaluation is based on individual manager or manager board rather than basing on job descriptions. The assessment to workers' managers is not performed by employees in Vietnamese companies. This might reduce the opposite points of evaluation works. As a result, this might cause the disadvantages of innovation in companies' managers.

\section{Training skills}

There are not many enterprises having the strategy plan of training for their workers. They seem to focus on training the senior managers and experts. The lower workers such as technicians and workers have to train or improve their skills by themselves. Besides that, many Vietnamese currently have not got a complete salary payment regulation for their employees

To sum up, the efficiency of management in human resources in Vietnamese companies is quite low. This needs to improve to update and meet the rapidly developing economy. To deal with this, the human resource management needs to be focused on as well as interested in Vietnamese companies in order to make an effective use of the labor resources in the enterprise.

B. Machine Learning in Human Resource management

Compared to other fields in economical society, human resources seems to be slower applying with machine learning or artificial intelligence (AI) than the other. However, if it can be used, the results are significant. For example, the use of machine learning techniques can predict employee contributions via KPI (Key Performance Indicator) or using machine learning in the recruitment process in the companies.

The improvements of machine learning such as in natural language processing contribute impressive applications. For example, intelligent chat bots which can handle some HR functions. Some companies use machine learning as intelligent assistants to support users in scheduling, project development planning or general communications instead of traditional methods [12], [9], [10].

Some human resource functions can be used with the help of machine learning are [17]:

- Create a schedule to make the interviews, group meetings in the system. Sometimes, the function might be a host of HR tasks in general.

- Produce a report on analytics related to HR data

- Rationalize workflows

- Enhance recruitment process

- Minimize the staff movement

- Train individually plan

- Monitor the cooperation and assessment

- Improve rewards and recognition programs

According to [5], the applicant of using machine learning in human resource is tracking and assessment. It has been recorded as the top list in machine learning applications, in particular it can work well with companies having high volumes of applicants. The machine learning techniques can help human resource staffs to hire new candidates by tracking their journey from starting job applying application to the interview process. The machine learning tools also can help to arrange the process of getting streamlined feedback to applicants. There are some free and open-source applications for users can be seen as [16]:

- Fresh-team: this software is used with a small number of employees as well as alternative companies.

- Open-CATS: It is usually used with technical firms. It is used as software for customization and systems integration.

- Job-Score: It uses for regulated industries which can check the background within ATS software

- Home-base: This software is usually used for restaurants and retailers. It focuses on finding hourly workers. 
AI in particular with machine learning can boost individual skill management and development via workers' self-training application. For example Workday ([19] - an enterprise cloud applications for finance and human resources ) can be seen as a recommendation of building personalized training. The company's needs, market trends, and employee specifics are the main factors of building the application.

\section{PROPOSED WORK}

The goal of human resource analytics is improving the human resource units in alternative departments in the company in order to achieve outcomes overall. The use of machine learning techniques might help to category the employees to improve their works as well as their promotions. KPI (Key Performance Indicator) is a term of job performance evaluation index. The machine learning techniques can be seen as a tool used with data, ratios, quantitative indicators for measurement of work for employees. Therefore, the KPI reflects the performance of organizations or functions or individuals.

In general, the use of KPIs for human resource management activities contributes to businesses and employees' sides. The supporting issues can be seen as:

- For the company: Monitor employee performance intuitively, transparently, accurately as well as propose appropriate salary, reward and discipline regimes. It can improve the efficiency of the acceptance work process. It ensures goals and visions can be completed as company expectations.

- For employees: Understand the level of completion of the work compared to the set goals. It is a tool to motivate working to achieve the goal. It can detect defects if the task is behind schedule for timely improvement.

The framework of using machine learning in HRM can be seen in Fig. 5. The steps as follows:

\section{Step 1: KPI builder:}

In this step, the company defines the persons, who have responsibilities for building employees' KPI. There are two methods to perform as:

- The functional departments directly build the KPIs system for positions of individuals in that department. For this, the human resource management team plays a supporting role as well as providing guidance to ensure KPIs comply with the company's rules/policies. The advantages of this method is that KPIs will be highly feasible and clearly show the functions and tasks of the department. However, if the department sets its own goals, there will often be a situation of lack of objectivity or sometimes the setting goals are too low. So, if a company uses this method, it is necessary to have the assessment and evaluation of the human resources team and senior management team.

- The human resources department or senior management team provides a set of KPIs for other departments in the company. Unlike the above method, it will ensure the objectivity and science of the method. However, the given KPIs may not be realistic or not properly represent the functions and duties of the department. To overcome this, the KPIs system, after being built, needs to be appraised and evaluated by functional departments in the company. Framework of using machine learning techniques in KPI assessment can be seen as the Fig. 5:

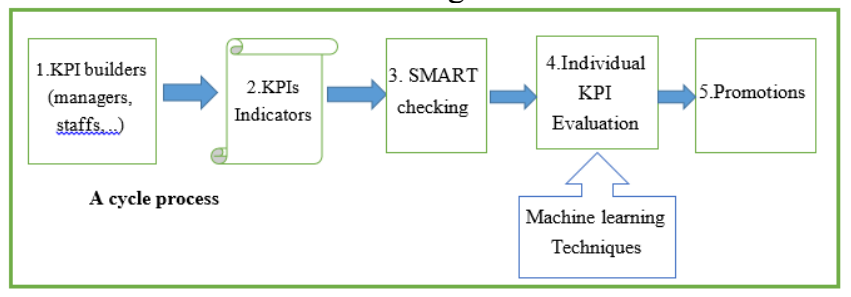

Fig. 5: Framework of using ML in HRM.

Step 2: KPI Indicators:

In this step the Indicators will be created basing on the following factors:

- Business vision: here the general tasks and objectives are shown clearly in order to achieve the business goals.

- At each general task, the details of sub-tasks or subobjectives are divided. These are KPI indexes.

- From each KPI index, the descriptions of individual tasks are written for each position in the functional department. These tasks are also the requirements for individuals in the evaluation stage.

Step 3: SMART checking:

After building KPIs indicators which are agreed with the functional department, the SMART criteria should be used to evaluate the tasks. The meaning of SMART can be seen as follows:

- S- Specific: Specific goal

- M-Measurable: Measurable goal

- A - Attainable: The goal is achievable

- R-Relevant: Realistic Goals

- T-Time bound: A goal with a specific deadline SMART in here means that the task can be reached to a detailed objective. In general, it can be used to measure the company's goals. The goal in KPIs indicator is achievable, realistic, and having a specific deadline. The KPIs should be built to satisfy the SMART criteria because they adversely affect the evaluation as well as the human resource management system. In case, the business goal in KPIs is not to clarify clearly the criteria (in specific indicator), it will be difficult for employees to do their jobs in order to achieve the desired work efficiency. Additionally, the indicators of KPIs should be measurable because the performance consequence has to be meaningful. Thirdly, the KPIs are not achievable or unrealistic, that means the employees cannot achieve their KPIS despite their best efforts. In other words, the KPIs have a very high goal so that the employees can not reach. As a result, employees might feel to be not happy to work and this affects psychologically and causes fatigue. Lastly, the KPIs should have specific deadlines (in Time-bound). This helps employees know the time to complete their work. Conversely, the system will be difficult to control what the employee's doing. 
Step 4: Individual KPI Evaluation:

Once the companies have their own KPIs for each department and job position, it's time to apply the KPIs system into management of both human resources and productivity. As KPIs have been defined based on measurable criteria, there is certainly a specific evaluation method for each KPI item.

Also at this step, the automatic machine learning techniques such as clustering algorithms are used to categorize workers into alternative groups. Some techniques are used here such as K-means cluster or Association rules which divide individual KPIs into exactly, unbiased groups based on their achievements (individual KPIs).

Clustering techniques usually are used to partition data into groups, or clusters. The group data objects in the same clusters will have many characteristics more than other groups in other clusters. There are many methods to define the number of clusters. Here, a number of clusters can be taken from users before going to the learning process. This depends on companies' decision of dividing how many groups of KPI's evaluate their workers. In general, evaluation of individual KPI can be divided into 3 main groups as follows:

- Group 1: takes less time, less impact

- Group 2: takes little time to implement and a little affects the overall goal; OR/AND takes a long time to implement, has little impact on the overall goal.

- Group 3: takes a long time to implement, greatly affects the overall goal.

The main steps in machine learning techniques as follows:

- 4.1. Step 1: Choose the number of clusters $K$ (normally $\mathrm{K}=3$ for example)

- 4.2. Step 2: Select K random points from the data as centroids

For example, we randomly select the centroid for each cluster $(\mathrm{K}=3)$.

- 4.3. Step 3: Assign points to the closest cluster centroid by calculating the Euclidean distance. This means whenever we initialize the centroids, the points in attribute spaces will be arranged into different areas where each point is assigned to the closest cluster centroid. In Fig. 7, the sample points will be assigned to 3 clusters according to closest distance from them to the centroid. We have temporary three clusters according to three colors and shapes.

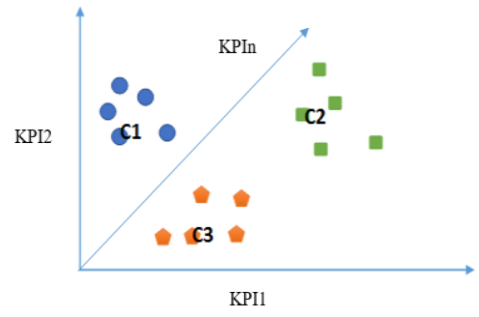

Fig. 6: Choose 3 centroids in KPI dimensional space.

- 4.4. Step 4: Re-compute the centroids of newly formed clusters. This step is to compute the centroids of newly formed clusters. For example, new centroids are found (see in Fig. 7).

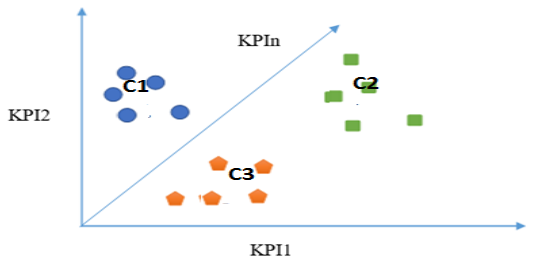

Fig. 7: Re-calculated centroids in KPI dimensional space

- 4.5. Step 5: Repeat steps 3 and 4.

At the end of the learning process, the clusters are collected (see in Fig. 8).

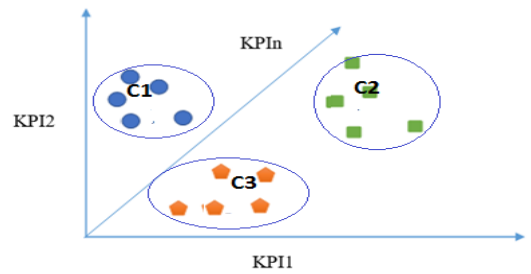

Fig. 8: Three clusters (groups) of KPIs in the system

The outputs of using machine learning techniques are the detail groups which contain individual KPIs values. Based on companies' policies e.g. the importance effects to the business goal, the weights might be applied at each group. For example, group 1 contributes $20 \%$ of weights; group 2: $30 \%$ and group 3 as $50 \%$.

Step 5: Promotions:

Based on the individual achievements in step 4, the companies will build alternative salary and bonus levels. In general, there is a meeting to evaluate the work results between the manager board, human resource teams, and employees.

The KPIs usually are adjusted occasionally in companies for achieving the optimization ones. In general, the KPIs system can be applied to a company's policies of promotions for a year at least.

\section{DISCUSSIONS}

Artificial Intelligence, nowadays, has been applied in many fields of human resources. The human resource management system using $\mathrm{AI}$ in particular machine learning techniques which can help the companies to find the right candidates, manage the assessments, give offers, and manage employee careers and exits. Before machine learning was used, human resources used to manage data in a manual and semiautomated manner. It causes difficulty in managing human resources. However, with the development of social networks as well as the eruption of information, all of the above needs to be done in a short period of time. Therefore, a human resource with the help of technology such as machine learning should be used. This can help the companies' manager board to quickly monitor, manage, and deliver their human resource efficiently because the data would quickly become irrelevant and out of date.

Vietnam has not got the needed skill labor to meet the highquality labor force although Vietnam has a young-age population. Not many Vietnamese companies concentrate on developing long term human resource planning. If the 
individual workers' performance is evaluated regularly, there will be a further labor picture for companies in the labor force. It can help companies to have an overview of the needed workforce in the future. From there they can be proactive in restructuring labor, arranging and organizing personnel as well as having a plan to recruit personnel.

In the $4.0^{\text {th }}$ technology revolution era, the companies' leaders prefer to manage their employees via data-driven performance management. It can help them to concentrate on the current work information as well as the reviewing of employees' performances. Before making decisions about individual workers' promotions there is a need for employees to collaborate with companies' leaders. To evaluate workers fairly and unbiasedly without interference by human effects, AI in particular machine learning techniques should be applied. The benefits of using machine learning in human resource performance management system can be seen as follows:

- Centre Information: Using this system to ensure that all the information has been stored in one single domain (normally in company's servers). The information or employee data can help companies and related parties can evaluate employee performance or/and share with the others at any time.

- Extract information at the real-time analysis: The information system can help the companies extract employees' KPI information in real-time via its analysis tools. Therefore, the system might help to improve overall employees' performance.

- Eliminate any form of psychological bias: As using machine learning techniques, the evaluation individual KPI performance is performed automatically. This means that no one can interfere with the system. The clustering of individual workers' performance results will be done without the intervention of any individual outside the system. The machine learning techniques ensure that the similar performance results will belong to the same group of promotions.

IV. CONCLUSIONS AND FUTURE WORK

There is no denying the great influence of AI, especially machine learning, in the human resource management field. Many companies have not yet applied modern human resource management methods, partly due to a lack of implementers, and partly due to prioritizing investment in the production and business system, which has consumed a lot of time and efforts of enterprises. Moreover, it also depends on the level of managers, who might be better at technical company's operations than personal management. In order to keep up with the trend of applying modern techniques of the Industry 4.0 era, companies should invest appropriately in human resource management, in which the factor of assessing human quality through KPIs is a core. That will promote the adaptability of human resources, increase competitiveness within the company itself, and create human strength throughout the company.

In this paper, the framework for the HRM information system has been proposed. It can be seen as the general steps for using machine learning techniques in HRM. For future work, this framework needs to be used and evaluated with the KPI real data from a company in order to show the advantage of using machine learning such as clustering techniques. To improve the disadvantage of clustering techniques on difficult explanations of results, another technique such as association rules also should be performed.

\section{REFERENCES}

[1] Benbya, H., \& McKelvey B. 2006. Using coevolutionary and complexity theories to improve IS alignment: A multilevel approach. Journal of Information Technology, 21(4), 284298

[2] Benbya, H., Nan, N., Tanriverdi, H., \& Youngjin, Y. 2020. Complexity and information systems research in the emerging digital world. MIS Quarterly, 44(1), 1-17.

[3] Bích Ngọc. 2019. Việt Nam: Mức độ sẵn sàng tham gia Cách mạng công nghiệp 4.0. Tạp chí Con số và sự kiện, Tổng cục Thống kê, Bộ Kế hoạch và Đầu tư - ISSN 2734 -9144. Available at website: http://consosukien.vn/viet-nam-muc-do-san-sang-tham-gia-cachmang-cong-nghiep-4-0.htm

[4] Chu Thị Bích Ngọc. 2018. Nâng cao chất lượng nguồn nhân lực Việt Nam trong cuộc CMCN 4.0, Tạp chí Tài chính, Availabe at website http://tapchitaichinh.vn/nghien-cuu--trao-doi/trao-doi-binh-luan/nangcao-chat-luongnguon-nhan-luc-viet-nam-trong-cuoc-cach-mang-congnghiep-40-147363.html

[5] Daniel, F. 2019. Machine Learning in Human Resources - Applications and Trends. Available at website: https://emerj.com/ai-sectoroverviews/machine-learning-in-human-resources/

[6] Daugherty, P., \& Wilson, H. J. 2018. Human + machine: Reimagining work in the age of AI. Harvard Business Review Press.

[7] Davenport, T. 2018. The AI advantage: How to put the artificial intelligence revolution to work. MIT Press.

[8] Deloitte. 2020. Thriving in the era of pervasive AI: Deloitte's state of

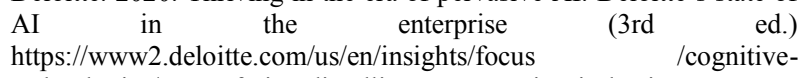
technologies/state-of-ai-andintelligent-automation-in-businesssurvey.html

[9] Gregor, S., Lin, A. Gedeon, T., Riaz, A. and Zhu, D. 2014. Neuroscience and a nomological network for the understanding and assessment of emotions in information systems research. Journal of Management Information Systems, 30(4),13-47.

[10] Gregory, R. W., Henfridsson, O., Kaganer, E., \& Kyriakou, H. 2020. The role of artificial intelligence and data network effects for creating user value. Academy of Management Review, 30(4), 13-47.

[11] Hppy, 2016. the white paper and see how you can create an integrated, engaging employee experience using people analytics. Availabel at website: https://gethppy.com

[12] Julia, M. 2020. How Machine Learning is Changing HR Industry. Availabe at website: https://codetiburon.com/machine-learningchanging-hr-industry/

[13] Murray, A. Rhymer, J., \& Simon, D. (in press). Humans and technology: Forms of conjoined agency in organizations. Academy of Management Review.

[14] Nguyễn Thị Bích Loan. 2018. Báo cáo tổng kết hội thảo "CMCN 4.0: Cơ hội và thách thức đối với phát triển kinh tế Việt Nam”. Đại học Thương mại.

[15] Nguyễn Trọng Hoài. 2018. Quốc tế hóa giáo dục Việt Nam: đào tạo nguồn nhân lực trong bối cảnh $\mathrm{CMCN}$ 4.0, Conference proceeding of "Nhu cầu nhân lực chất lượng cao cho phát triển trong bối cảnh CMCN 4.0 ", page $236-252$.

[16] Olga,Y. 2020. How to Create an Applicant Tracking System and Improve Your Recruitment Process. Availabe at website: https://codetiburon.com/how-to-build-an-applicant-tracking-system/

[17] Sarah, W. 2021. The Impact Of Machine Learning In HR. Available at website: https://gethppy.com/hrtrends/the-impact-of-machinelearning-in-hr

[18] Trần Mai Đông et al. 2018. Tác động của cuộc CMCN 4.0 đến đời sống xã hội và dịch chuyển cơ cấu nguồn lao động, Conference proceeding of "Nhu cầu nhân lực chất lượng cao cho phát triển trong bối cảnh CMCN 4.0". Page: $181-189$.

[19] workday Inc. 2021. Availbale at website: https://www.workday.com [20] https://www.statista.com/ 